\title{
Notice of retraction of abstract
}

Ceylon Medical Journal 2011; 56: 188

The following abstract of the presentation made at the 2011 Annual Scientific Sessions of the SLMA is retracted on the request of the authors.

\section{Abstract OP - 34}

Factor 5 Hong Kong and Cambridge mutations are absent in patients with deep vein thrombosis. Hidellage NT, Goonasekara HWW, Jayasekera RW, Wijesundare WSS, Dissanayake VHW. Human Genetics Unit and Department of Biochemistry and Molecular Biology, Faculty of Medicine, University of Colombo. CMJ 2011; 56 (Supplement 1): p32.

Joint Editors, CMJ 